\title{
Investigation on Risk Factors of Chronic Gastritis in the Population of Conakry in Guinea
}

\author{
Y. CHENG*, M. KEITA ${ }^{1}$ AND X. B. SI \\ Department of Gastroenterology, Beijing Jishuitan Hospital, No. 31 Xinjiekou East Street, Xicheng District, Beijing 100035, \\ China; 1Department of Internal Medicine, Sino Guinean Friendship Hospital
}

\section{Cheng et al.: Investigation on risk factors of chronic gastritis}

\begin{abstract}
To analyze risk factors for the development of chronic gastritis in Conakry, Guinea, and to provide a basis for its prevention and control. A case group of patients who had a gastroscopy and a gastroscopy report at the Sino-German Friendship Hospital in Conakry from January 2019 to January 2020 was selected, while a control group of 107 patients with chronic lung diseases and other chronic diseases of the digestive system were selected. Factor logistic regression analysis of risk factors. The results show that chronic gastritis affects people aged 11 to $95 \mathrm{y}$, with the highest proportion of patients aged 18 to $30 \mathrm{y}, 80$ $\%$ of whom live in rural areas. The main risk factors for gastritis in the Conakry region of Guinea were a history of digestive problems, smoking for more than $10 \mathrm{y}$, fast eating, eating hot food at least once a week, and eating moldy food at least once a week. Protective factors against gastritis in Guinea Conakry are: regular diet. The adjusted population-attributable risk for the main risk factors for gastritis were a history of digestive problems $61.19 \%$, eating too fast $23.59 \%$, smoking for more than 10 y $26.60 \%$, eating hot food at least once a week $24.76 \%$ and eating mouldy food at least once a week $6.87 \%$. The combined population-attributable risk for these factors was $79.07 \%$. A history of digestive disease, a smoking history of more than $10 \mathrm{y}$, fast food intake, hot food at least once a week and moldy food at least once a week were risk factors for the development of chronic gastritis in Guinea Conakry, and regular diet was a protective factor against the development of chronic gastritis in young and middle-aged patients in Guinea Conakry.
\end{abstract}

Key words: chronic gastritis, Guinea Conakry, risk factors, Sino-guinean friendship hospital

Chronic gastritis, as a common and frequently occurring clinical disease, is a chronic inflammation caused by multiple factors that damage the gastric mucosa. The diagnosis rate of chronic gastritis in Africa accounts for $90 \%$ of all endoscopic patients ${ }^{[1]}$. Studies have shown that Helicobacter pylori (HP) infection is the main pathogenic factor of chronic gastritis ${ }^{[2]}$. At present, most studies focus on the pathogenic mechanism of HP, but few studies on the epidemic of HP infection and post infection ${ }^{[3]}$. So far, the pathogenesis of chronic gastritis is still unclear. According to the theory of traditional Chinese medicine, the main pathogenic factors of this disease are improper diet, leisure, exogenous factors, seven emotions and other diseases transmission and so on. The etiology of the disease in modern medicine is summarized as long-term intake of rough and irritating food, alcohol, salty food, drugs that damage the stomach and radiotherapy of tumor ${ }^{[4]}$. The above two theories have a lot of consistency. However, the risk factors of chronic gastritis have great regional differences ${ }^{[5,6]}$. Therefore, according to the international DME standard, the investigation of chronic gastritis in Conakry, Guinea, is of great significance to analyze the relationship between etiological risk factors and physical fitness, and draw more objective conclusions through the analysis, so as to put forward reasonable plans or suggestions for the prevention and treatment of chronic gastritis. A total of 115 patients who had received gastroscopy were selected from January 2019 to January 2020 in Conakry China Friendship Hospital, of which 56 female patients and 59 male patients were selected, the age range was from 11 to $95 \mathrm{y}$ old, with an average age of $43 \mathrm{y}$. All patients were diagnosed as chronic gastritis by gastroscopy, with gastric mucosal edema, bleeding spots, red and white, mucous membrane with mucus, mucosal biopsy showed inflammatory cell infiltration. The control group included 107 cases of normal people, patients with 
chronic pulmonary diseases and other chronic diseases of digestive system, including 59 males and 48 females, aged 13-90 y, with an average age of $(41.8 \pm 5.1) \mathrm{y}$. There was no significant difference in gender composition and age between the two groups ( $p>0.05)$. Acute gastric mucosal lesions and gastric mucosal malignant lesions were excluded. Referring to the related reports on the risk factors of chronic gastritis, the self-made questionnaire was used to investigate the patients, and the epidemiological personnel were responsible for the examination. The main contents of the survey include: education level, income, smoking, drinking and eating on time, preference for hot food, frequent eating of fruits, overeating, stress and anxiety. All the respondents were given unified training and the use standard was consistent. The questionnaire should be filled in truthfully and recycled immediately after filling in. The smoking index was calculated by the number of cigarettes smoked per day $\times$ the number of years of smoking, and the drinking index was calculated by the number of grams of alcohol consumed per day $\times$ the number of years of drinking. Both the case group and the control group were asked by the unified questionnaire, and each questionnaire was strictly reviewed by the quality controller. If there are unqualified filling items, they must be supplemented or excluded as invalid questionnaires, so as to avoid or reduce the deviation from the investigators as far as possible. All the data were analyzed by Statistical Package for the Social Sciences (SPSS) 20.0 software. The count data were represented as percentage or rate (\%). Chi square test was used to compare multiple groups. Univariate and multivariate logistic regression were used to analyze risk factors. $\mathrm{P}<0.05$ was considered as statistically significant difference. Among the 115 cases, the age of patients with chronic gastritis ranged from 11 to $55 \mathrm{y}$ old, of which (47) $40.87 \%$ were $18-30$ y old, $27.83 \%$ were over 60 y old, $13.04 \%$ were $30-45$ y old, $11.30 \%$ were $45-60$ y old, and $6.83 \%$ were under 18 y old. In the case group, there were 23 cases living in urban communities, accounting for $20.0 \%$, and 92 cases living in villages and towns, accounting for $80.0 \%$. As shown in fig. 1. The results of univariate analysis showed that the related factors of gastritis in Conakry area were: family member relationship $(\mathrm{p}=0.001)$, mental health before illness $(p<0.001)$, history of digestive system diseases $(p<0.001)$, family history of gastropathy $(p=0.011)$, smoking $(p=0.041)$, eating too fast $(p<0.001)$, overeating $(p<0.001)$, and eating regularly The patients were fed spicy food $(p=0.023)$ (Table 1$)$. The variables with statistical significance in univariate analysis and those not statistically significant in univariate analysis but clinically significant were included in conditional multivariate logistic regression analysis. The results were as follows: The main risk factors of gastritis in Conakry area: history of digestive system diseases $(\mathrm{p}<0.001)$, Odds ratio (OR) $(95 \%$ Confidence interval (CI)) of 28.636 (11.384, 72.033); smoking age more than $10 \mathrm{y}$ less than $20 \mathrm{y}(\mathrm{p}=0.016)$, OR $(95 \% \mathrm{CI}) 1.805$ $(1.342,16.753)$; eating too fast $(\mathrm{p}=0.006)$, OR $(95 \%$ CI) $3.846(1.481,9.985)$; eating at least 3 times a $w$, the OR $(95 \%$ CI) was $10.254(2.026,51.891)$, the OR (95 $\% \mathrm{CI})$ was $10.254(2.026,51.891)$ and the OR $(95 \%$ CI) was $10.305(2.46,43.162)$ respectively. Protective factors of gastritis: regular diet $(\mathrm{p}=0.017)$, OR $(95 \%$ CI) was $0.444(0.228,0.865)$ (Table 2). Multivariate logistic regression was used to calculate the main risk factors of gastritis in Conakry area. The results were as follows: the history of digestive system diseases, eating too fast, smoking more than $10 \mathrm{y}$ and less than $20 \mathrm{y}$. The corresponding adjusted population attributable risk (PARC \%) of eating hot food and moldy food were $61.19,23.59,26.6,24.76$ and 6.87 , respectively. The overall population attributable risk (spar \%) was 79.07 (Table 3). At present, the etiology and pathogenesis of chronic gastritis are still unclear ${ }^{[7]}$. Changes in immune status after HP infection have great damage to gastric mucosa, and are known biological risk factors of chronic gastritis ${ }^{[8-10]}$. With the transformation of medical model from traditional biomedical model to biological social psychological medical model, people realize that in addition to biological risk factors, social and psychological factors also play an important role in the pathogenesis of chronic gastritis ${ }^{[11]}$. Our research results show that the incidence rate of gastritis is not positively correlated with age. It may be related to case selection or the irregular life of young people aged 18 30. The specific reasons for this need to be verified by largescale sampling. In addition, our results also revealed that the incidence of chronic gastritis in young and middle-aged patients in Beilun District was related to smoking for 10-20 y, which was a risk factor for the onset of chronic gastritis. Cigarette contains tar, nicotine and other harmful components, which can cause gastrointestinal mucosal dysfunction. Meanwhile, harmful smoke in cigarettes can cause dysfunction of gastric mucosal vasoconstriction, lead to gastric mucosal damage, and increase the risk of chronic gastritis ${ }^{[12]}$.Young and middle-aged people have more social intercourse and irregular life. Smoking and drinking should be reduced to reduce the risk of chronic 
Age

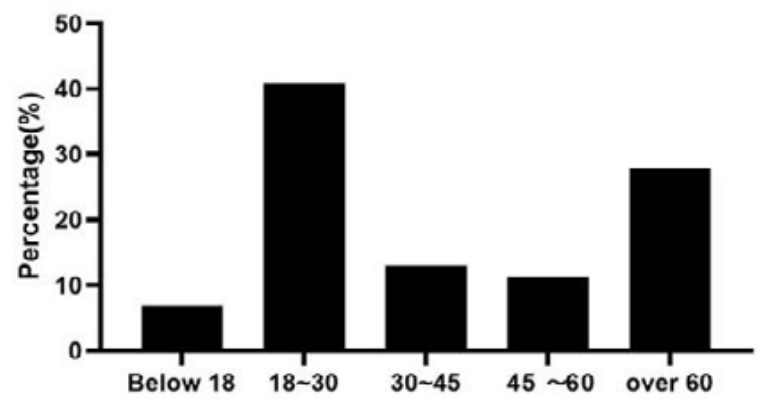

residents

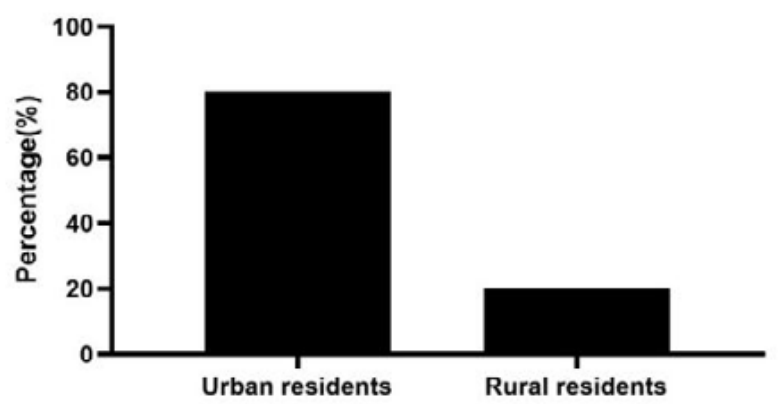

Fig. 1: Age and regional composition of patients with chronic gastritis in Conakry area

TABLE 1: SINGLE FACTOR ANALYSIS OF CHRONIC GASTRITIS

\begin{tabular}{|c|c|c|c|c|}
\hline Influence factors & Cases & Control & $x^{2}$ & $\mathrm{p}$ \\
\hline Family relationships (rapport/discord) & $89 / 26$ & $97 / 10$ & 11.152 & 0.001 \\
\hline Mental health before illness (Yes/No) & $78 / 37$ & $90 / 17$ & 27.906 & $<0.001$ \\
\hline History of digestive system diseases (Yes/No) & $65 / 50$ & $12 / 95$ & 163.152 & $<0.001$ \\
\hline Family history of gastropathy (Yes/No) & $21 / 94$ & $15 / 92$ & 6.468 & 0.011 \\
\hline Pollution sources within 500 meters of residence (Yes/No) & $8 / 107$ & $7 / 100$ & 0.093 & 0.761 \\
\hline Is the drinking water source polluted (Yes/No) & $0 / 115$ & $0 / 107$ & 0 & 1 \\
\hline Source of drinking water (treated tap water/non tap water) & $35 / 80$ & $30 / 77$ & 0.123 & 0.726 \\
\hline Smoking (Yes/No) & $82 / 33$ & $46 / 61$ & 4.179 & 0.041 \\
\hline length as a smoker $(<10 ;>10<20 ;>20 y)$ & $43 / 25 / 37$ & $43 / 24 / 45$ & 5.290 & 0.071 \\
\hline Drinking (Yes/No) & $62 / 53$ & $57 / 50$ & 0.895 & 0.344 \\
\hline Drinking time $(<10 ;>10<20 ;>20 y)$ & $55 / 9 / 51$ & $43 / 13 / 51$ & 1.261 & 0.532 \\
\hline Is eating too fast ((Yes/No) & $37 / 78$ & $18 / 89$ & 40.871 & $<0.001$ \\
\hline Overeating habits (Yes/No) & $62 / 53$ & $15 / 92$ & 33.339 & $<0.001$ \\
\hline Is the diet regular (Yes/No) & $57 / 58$ & $72 / 35$ & 20.729 & $<0.001$ \\
\hline Vegetables $(<1 ;<3 ; \geq 3$ times $/ w)$ & $3 / 10 / 102$ & $1 / 13 / 93$ & 1.393 & 0.498 \\
\hline Fresh fruits $(<1 ;<3 ; \geq 3$ times $/ w)$ & $28 / 62 / 25$ & $21 / 62 / 24$ & 1.727 & 0.422 \\
\hline Legume foods $(<1 ;<3 ; \geq 3$ times/w) & $14 / 54 / 47$ & $17 / 51 / 39$ & 5.675 & 0.059 \\
\hline Fried foods $(<1 ;<3 ; \geq 3$ times $/ w)$ & $46 / 41 / 28$ & $39 / 42 / 24$ & 1.652 & 0.438 \\
\hline Hot foods $(<1 ;<3 ; \geq 3$ times $/ w)$ & $65 / 31 / 19$ & $57 / 28 / 22$ & 3.385 & 0.184 \\
\hline Moldy foods $(<1 ;<3 ; \geq 3$ times $/ w)$ & $94 / 21 / 0$ & $93 / 12 / 2$ & 4.549 & 0.103 \\
\hline Spicy diet $(<1 ;<3 ; \geq 3$ times $/ w)$ & $37 / 35 / 43$ & $31 / 33 / 43$ & 7.572 & 0.023 \\
\hline Cool foods $(<1 ;<3 ; \geq 3$ times $/ w)$ & $62 / 31 / 22$ & $64 / 27 / 16$ & 2.415 & 0.299 \\
\hline
\end{tabular}

$\mathrm{x}^{2}$ : Chi-square Test

\section{TABLE 2: RESULTS OF MULTIVARIATE LOGISTIC REGRESSION ANALYSIS OF GASTRITIS}

\begin{tabular}{lcccc}
\hline Influence factors & $\mathrm{B}$ & $\mathrm{W}$ & $\mathrm{CP}$ & OR $(95 \% \mathrm{Cl})$ \\
\hline Digestive system diseases & 3.355 & 50.805 & $<0.001$ & $28.636(11.384,72.033)$ \\
Smoking years & 6.604 & 0.037 & & \\
$10<\mathrm{n}<20$ & 1.556 & 5.841 & 0.016 & $4.742(1.342,16.753)$ \\
$>20$ & 0.591 & 2.468 & 0.116 & $1.805(0.864,3.722)$ \\
Eating too fast & 1.347 & 7.657 & 0.006 & $3.846(1.481,9.985)$ \\
Diet pattern & -0.811 & 5.696 & 0.017 & $0.444(0.228,0.865)$ \\
Eating hot food & 7.926 & 0.019 & & \\
1 or 2 times/w & 1.518 & 5.479 & 0.019 & $4.562(1.280,16.257)$ \\
$>3$ times $/ \mathrm{w}$ & 2.328 & 7.916 & 0.005 & $10.254(2.026,51.891)$ \\
Eating moldy foods & 10.190 & 0.006 & & \\
1 or 2 times/w & 2.333 & 10.189 & 0.001 & $10.305(2.460,43.162)$ \\
$>3$ times/w & -19.104 & 0.001 & 0.977 & 0 \\
\hline B Regsing
\end{tabular}

B: Regression coefficient; W: Wald; OR: Odds ratio 
TABLE 3: POPULATION ATTRIBUTABLE RISK OF GASTRITIS RISK FACTORS UNDER MULTIFACTORIAL CONDITIONS

\begin{tabular}{lcccc}
\hline Influence factors & Level & OR & Cases & Adjust PAR (\%) \\
\hline Digestive system diseases & No & 1 & 50 & $61.19 \%$ \\
Digestive system diseases & Yes & 28.636 & 65 & \\
Eating too fast & No & 1 & 78 & $23.59 \%$ \\
Eating too fast & Yes & 3.846 & 37 & \\
& $<10 \mathrm{y}$ & 1 & 43 & $26.60 \%$ \\
Smoking years & $10<\mathrm{n}<20$ & 4.742 & 25 & \\
& $>20 \mathrm{y}$ & 1.805 & 37 & \\
Eating hot food & No & 1 & 65 & $24.76 \%$ \\
& $1-2$ times $/ \mathrm{w}$ & 4.562 & 31 & \\
Eating moldy food & $\geq 3$ times $/ \mathrm{w}$ & 10.254 & 19 & $6.87 \%$ \\
& No & 1 & 94 & \\
& $1-2$ times $/ \mathrm{w}$ & 10.305 & 21 & \\
& $\geq 3$ times $/ \mathrm{w}$ & 0 & 0 & $79.07 \%$ \\
\hline
\end{tabular}

OR: Odds ratio

gastritis. In addition, eating habits are also an important factor affecting the incidence of chronic gastritis. Not eating on time, preferring hot food and often overeating can increase the risk of chronic gastritis. Previous studies have shown that eating spicy food and overeating can increase the probability of HP infection, which is consistent with the research results ${ }^{[13]}$. The unhealthy eating habits such as eating on time, preferring hot food and overeating often may cause gastrointestinal dysfunction, gastric acid secretion disorder, and increase the risk of chronic gastritis. It has been reported that irregular eating habits can lead to neuroendocrine system disorders, increase stimulation of gastric mucosa and promote the occurrence of chronic gastritis ${ }^{[14]}$. Therefore, young and middle-aged people should eat on time, do not eat overheated food; do not overeat, in order to reduce the risk of chronic gastritis. Hiccup/ belching and acid reflux were both related to eating too fast, irregular mealtimes, eating leftover food, very hot foods, sweets, pickled foods, and salty foods. Guinea, as a developing country in Africa, is economically backward. A large part of the population still lives in the primitive tribal self-sufficiency economic life, and the economic and health conditions are very limited. Local tropical climate, lack of refrigerators, food mildew and deterioration. Moldy food has been proved to increase the risk of gastritis because of its carcinogenic substances such as nitrosamine, benzopyrene- $\alpha$ and mycotoxin, which has also been confirmed in this investigation. This survey found that moldy food is also a risk factor for gastritis, which has appeared many times in many studies on risk factors of gastritis ${ }^{[15-17]}$. Finally, a large number of N-nitrosamines in moldy food can cause gastric mucosal damage, inflammation and precancerous lesions. Wen denggui's study found that moldy food can increase the risk of non cardia gastritis, and these carcinogens and HP infection may have a synergistic effect, leading to the occurrence of gastritis. As a risk factor of gastritis, chronic HP infection can stimulate cell division and reproduction. On this basis, the intensity of action of carcinogens such as nitrosamine can be significantly increased, which leads to a significant increase in incidence rate of gastritis $^{[18]}$. The results of this study show that regular diet is a protective factor of gastritis, while in previous studies, irregular diet is an important risk factor for gastritis $^{[19-21]}$. There are physiological peaks and valleys in the secretion of gastric juice. Irregular diet will disturb the biological clock of intestines and stomach. If digestive juice such as gastric acid and pepsin cannot be neutralized in time, it will cause damage to gastric $\operatorname{mucosa}^{[22]}$. Moreover, irregular diet will lead to excessive secretion of gastric acid, the performance of pantothenic acid, and then cause superficial gastritis, leading to atrophic gastritis. Atrophic gastritis can provide an environment for the growth of Helicobacter pylori, which greatly increases the risk of gastric cancer. In conclusion, the present study confirmed that the main risk factors of gastritis in Conakry, Guinea, included the history of digestive system diseases, eating too fast, 
smoking more than $10 \mathrm{y}$ and less than $20 \mathrm{y}$, and the corresponding adjusted population attributable risk of eating hot food and moldy food (PARC \% were 61.19, $23.59,26.6,24.76$ and 6.87 , respectively). The overall population attributable risk (SPR \%) was 79.07, which indicated that $79.07 \%$ of the incidence of gastritis in Conakry, Guinea, was attributed to these factors. The incidence of gastritis in Conakry area of Guinea can be reduced by $79.07 \%$ if the adverse psychological status, history of digestive system diseases, overeating, eating pickled vegetables and eating moldy food is controlled at the same time.

\section{Conflicts of interest:}

The authors report no conflicts of interest.

\section{Acknowledgements:}

This work was supported by Beijing Jishuitan Hospital and Sino Guinean Friendship Hospital.

\section{REFERENCES}

1. Globocan WH. Estimated cancer incidence, mortality and prevalence worldwide in 2012. Int Agency Res Cancer 2012.

2. Fitzmaurice C, Dicker D, Pain A, Hamavid H, Moradi-Lakeh M, MacIntyre MF, et al. The global burden of cancer 2013. JAMA oncol 2015;1:505-27.

3. Peto J. Cancer epidemiology in the last century and the next decade. Nature 2001;411:390-5.

4. Danaei G, Vander Hoorn S, Lopez AD, Murray CJ, Ezzati M. Comparative Risk Assessment collaborating group (Cancers. Causes of cancer in the world: comparative risk assessment of nine behavioural and environmental risk factors. The Lancet 2005;366:1784-93.

5. Derakhshan MH, Malekzadeh R, Watabe H, Yazdanbod A, Fyfe V, Kazemi A, et al. Combination of gastric atrophy, reflux symptoms and histological subtype indicates two distinct aetiologies of gastric cardia cancer. Gut 2008;57:298-305.

6. Blankfield RP. Helicobacter pylori infection and the development of gastric cancer. N Engl J Med 2002;346:65-7.

7. Wang F, Zhang X, Wang J. Effects of domperidone in combination with omeprazole in the treatment of chronic superficial gastritis. PaK J Med Sci 2017;33:306-9.

8. Jeong S, Choi E, Petersen CP, Roland JT, Federico A, Ippolito $\mathrm{R}$, et al. Distinct metaplastic and inflammatory phenotypes in autoimmune and adenocarcinoma-associated chronic atrophic gastritis. United European Gastroenterol J 2017;5:37-44.

9. Yamasaki Y, Uedo N, Kanzaki H, Kato M, Hamada K, Aoi K, et al. Investigation of mucosal pattern of gastric antrum using magnifying narrow-band imaging in patients with chronic atrophic fundic gastritis. Ann Gastroenterol 2017;30:302-8.
10. Schistosomes IA. Liver flukes and Helicobacter pylori. IARC Monogr Eval Carcinog Risks Hum 1994;61:1-241.

11. Veldhuyzen van Zanten SJ, Pollak PT, Best LM, Bezanson GS, Marrie T. Increasing prevalence of Helicobacter pylori infection with age: continuous risk of infection in adults rather than cohort effect. J Infect Dis 1994;169:434-7.

12. Boeing H, Frentzel-Beyme R, Berger M, Berndt V, Gores $\mathrm{W}$, Korner M, et al. Case-control study on stomach cancer in Germany. Int J Cancer 1991;47:858-64.

13. Parkin DM, Boyd L, Walker LC. The fraction of cancer attributable to lifestyle and environmental factors in the UK in 2010. Br J Cancer 2011;105:S77-81.

14. Viani F, Siegrist HH, Pignatelli B, Cederberg C, Idstrom JP, Verdu EF, et al. The effect of intra-gastric acidity and flora on the concentration of N-nitroso compounds in the stomach. Eur J Gastroenterol Hepatol 2000;12:165-73.

15. Liu C, Russell RM, Wang XD. Lycopene supplementation prevents smoke-induced changes in p53, p53 phosphorylation, cell proliferation, and apoptosis in the gastric mucosa of ferrets. J Nutr 2006;136:106-11.

16. Seki T, Hosono $\mathrm{T}$, Hosono-Fukao $\mathrm{T}$, Inada $\mathrm{K}$, Tanaka R, Ogihara $\mathrm{J}$, et al. Anticancer effects of diallyl trisulfide derived from garlic. Asia Pac J Clin Nutr 2008;17:4.

17. Powolny AA, Singh SV. Multitargeted prevention and therapy of cancer by diallyl trisulfide and related Allium vegetablederived organosulfur compounds. Cancer Lett 2008;269:30514.

18. Mayne ST, Risch HA, Dubrow R, Chow WH, Gammon MD, Vaughan TL, et al. Nutrient intake and risk of subtypes of esophageal and gastric cancer. Cancer Epidemiol Biomarkers Prev 2001;10:1055-62.

19. Derakhshan MH, Malekzadeh R, Watabe H, Yazdanbod A, Fyfe V, Kazemi A, et al. Combination of gastric atrophy, reflux symptoms and histological subtype indicates two distinct aetiologies of gastric cardia cancer. Gut 2008;57:298-305.

20. Correia M, Machado JC, Ristimäki A. Basic aspects of gastric cancer. Helicobacter 2009;14:36-40.

21. Kim H, Eun JW, Lee H, Nam SW, Rhee H, Koh KH, et al. Gene expression changes in patient-matched gastric normal mucosa, adenomas, and carcinomas. Exp Mol Pathol 2011;90:201-9.

22. Ladeiras-Lopes R, Pereira AK, Nogueira A, Pinheiro-Torres T, Pinto I, Santos-Pereira R, et al. Smoking and gastric cancer: systematic review and meta-analysis of cohort studies. Cancer Causes Control 2008;19:689-701.

This is an open access article distributed under the terms of the Creative Commons Attribution-NonCommercial-ShareAlike 3.0 License, which allows others to remix, tweak, and build upon the work non-commercially, as long as the author is credited and the new creations are licensed under the identical terms

This article was originally published in a special issue, "Clinical Research in Pharmaceutical and Biomedical Sciences" Indian J Pharm Sci 2021:83(1)Spl issue1;1-5 